\title{
Análise ambiental do uso de fontes de nutrientes associadas a sistemas de manejo do solo ${ }^{1}$
}

\author{
Carla M. Pandolfo ${ }^{2}$, Carlos A. Ceretta ${ }^{3}$, Angelo M. Massignam² ${ }^{2}$ Milton da Veiga ${ }^{2} \&$ Isabel C. L. Moreira ${ }^{4}$
}

\section{RESU M O}

Os modelos matemáticos de análises são ferramentas integradoras que podem contribuir para uma avaliação mais eficaz do potencial poluente de dejetos quando dispostos no ambiente. Utilizou-se, para avaliar os impactos do uso de fontes de nutrientes, um experimento conduzido durante nove anos, em um Nitossolo Vermelho Distrófico, com uma combinação de aplicação de cinco fontes de nutrientes (três fontes orgânicas, uma mineral e uma testemunha) associadas a cinco sistemas de manejo do solo, com delineamento em blocos subdivididos e três repetições. Os atributos utilizados foram os teores no solo de Zn e Cu disponíveis, formas lábeis de P, índice de diversidade da mesofauna edáfica, teores de carbono e nitrogênio no solo, além de dois questionários de opinião sobre o impacto ambiental do uso dos dejetos e dos sistemas de manejo do solo. $\mathrm{Na}$ aval iação se usou um modelo cujas saídas, para cada fonte de nutriente dentro de cada sistema de manejo do solo, foram figuras triangulares e a área das mesmas, com intervalo de confiança a nível de $90 \%$. As fontes orgânicas exerceram efeitos diferenciados quanto ao aspecto ambiental, em que 0 dejeto líquido de suínos apresentou o pior desempenho. 0 índice de risco, dentre os três índices que compõem 0 aspecto ambiental, demonstrou ser o mais crítico ao ambiente, considerando-se os parâmetros e pesos utilizados.

Palavras-chave: dejetos, resíduos orgânicos, modelo de análise

\section{Environmental analysis of use of different sources of nutrients associated with soil tillage systems}

\begin{abstract}
Integrated analysis models can contribute to more efficient evaluation of the pollutant potential of sludge disposed in the environment. In order to study these aspects, an experiment was carried out for nine years on an 0 xisol to evaluate five nutrient sources (three organic, one mineral, and a control) associated with five tillage systems in a subdivided block design, with three replications. The attributes used were available $\mathrm{Cu}$ and $\mathrm{Zn}$, labile P compounds, diversity index of soil mesofauna, total $\mathrm{N}$, and organic carbon content, as well as two questionnaires asking for technical opinions about the environmental impact of nutrient sources and soil tillage. In this evaluation a model was used which outputs, for each nutrient source within each soil tillage system, triangular figures and their areas, with a confidence interval of $90 \%$. The nutrient sources were different regarding the environmental aspect, and the pig slurry was the worst source among them. Among the three indexes which took part in the environmental aspect, environmental risk index was the most critical considering the parameters and weights used.
\end{abstract}

Key words: manure, organic residues, analysis model

\footnotetext{
1 Parte da Tese de Doutorado do primeiro autor

2 Empresa de Pesquisa Agropecuária e Extensão Rural de Santa Catarina/EPAGRI, CP 116, CEP 89620-000, Campos Novos, SC. Fone: (49) 3541-0748. E-mail: pandolfo@epagri.sc.gov.br

3 Departamento de Solos/UFSM, CEP 97105-900, Santa Maria, RS. Fone: (55)_3220-8108. E-mail: carlosceretta@smail.ufsm.br

${ }^{4}$ Rua Dr. Bozano 968/802, Centro, CEP 97015-002, Santa Maria, RS, Fone: (55) 3221-4644. E-mail: isabellm@yahoo.com.br
} 


\section{INTRODUÇÃO}

A criação de bovinos, suínos e aves, tem sido uma alternativa economicamente expressiva nas propriedades do sul do Brasil. Estimou-se, em 2003, que no Estado de Santa Catarina o rebanho efetivo de bovinos, suínos e aves era de aproximadamente 3,2; 108 a 115 e 5,5 milhões de cabeças, respectivamente, conforme o Levantamento Agropecuário de Santa Catarina 2002-2003 (ICEPA/SC, 2005). O aumento desse rebanho e a concentração da atividade ao longo dos anos, sobretudo a suinícola, têm levado a um acréscimo do volume de dejetos e de sua aplicação no solo como fertilizante, muitas vezes em quantidades elevadas. Isto ocorre em função da aplicação de doses em função do elemento mais limitante, considerando-se os teores no solo e a necessidade da cultura. O uso do solo e das águas superficiais para descarte do excedente, quando ocorre, aumenta o potencial de poluição pelos dejetos. No solo, aplicações freqüentes resultam no acúmulo de alguns elementos. Dentre os elementos potencialmente poluidores, os metais pesados são importantes em virtude de se acumularem no solo e apresentarem possibilidade de inserção na cadeia alimentar (Muchovej \& Obreza, 1996). Os dejetos também podem resultar na transmissão de patógenos, como as bactérias fecais e os protozoários no solo e na água (McMurry et al., 1998; Stoddard et al., 1998; Hunter et al., 2000), eutrofização das águas superficiais e contaminação do lençol freático por nitrato, entre outros (Chang et al., 1991; Bouchard et al., 1992; Angle et al., 1993; Moore Jr. et al., 1995; Sharpley et al., 1995). A magnitude dos problemas ambientais devido ao uso dos dejetos também depende do preparo do solo utilizado (Angle et al., 1993; Stoddard et al., 1998).

Apesar dos possíveis problemas decorrentes do uso dos dejetos como fonte de nutrientes, seu uso na produção agrícola se constitui em uma opção tecnicamente viável e recomendável, desde que observados os riscos potenciais ao solo e ao ambiente. Fatores como o tempo, doses e métodos de aplicação desses insumos, podem resultar em degradação ambiental, especialmente da água (Muchovej \& Obreza, 1996). O que, no entanto, também pode acontecer quando do uso inadequado de fertilizantes minerais.

O impacto ambiental do uso de fontes de nutrientes aplicadas em períodos de médio e longo prazos, pode ser melhor avaliado utilizando-se atributos integrados que levam em conta possíveis efeitos danosos e/ou benéficos da utilização dos dejetos como fonte de nutrientes às plantas, quando aplicados em diferentes sistemas de manejo do solo. A avaliação integrada de vários atributos ou variáveis pode ser útil para as recomendações de uso das fontes, evidenciando a potencialidade de dano (pontos negativos) e/ou de melhoria ao ambiente (pontos positivos), considerando-se a forma como cada dejeto é utilizado ou em que sistema de manejo do solo ele será empregado. O tipo de manejo do solo condiciona a incorporação dos resíduos vegetais e a degradação da matéria orgânica (Etana et al., 1999) e pode afetar a eficiência das fontes orgânicas e minerais de nutrientes. A retirada de material vegetal para silagem ou fenação, bem como a queima dos resíduos, em geral deixam a superfície do solo prati- camente sem proteção contra os agentes erosivos, independente do sistema de manejo. A adição de materiais orgânicos ao solo pode minimizar os efeitos adversos da retirada dos resíduos ou da sua queima. Quando os resíduos vegetais são mantidos na lavoura, a adição de dejetos pode aumentar a produção das culturas, pelo suprimento de nutrientes durante sua decomposição (Scherer et al., 1984; 1991).

$\mathrm{O}$ balanço entre a potencialidade de dano e a melhoria do ambiente pelo uso de fontes orgânicas e minerais de nutrientes, foi denominado aspecto ambiental; neste sentido, o objetivo do trabalho foi avaliar o aspecto ambiental do uso de fontes de nutrientes associadas a sistemas de manejo do solo.

\section{MATERIAL E MÉTODOS}

Um experimento conduzido durante nove anos na Estação Experimental da EPAGRI, em Campos Novos, no Planalto Sul Catarinense ( $27^{\circ} 24^{\prime} \mathrm{S}, 51^{\circ} 13^{\prime} \mathrm{O}, 970 \mathrm{~m}$ de altitude) em um Nitossolo Vermelho Distrófico (EMBRAPA, 2006), foi utilizado para realização deste estudo. O delineamento experimental foi em blocos subdivididos com três repetições sendo que, em cada bloco, os sistemas de manejo do solo foram aplicados em faixas transversais ao declive do terreno e as fontes de nutrientes em faixas transversais aos sistemas de manejo, ambas com $6 \mathrm{~m}$ de largura e $30 \mathrm{~m}$ de comprimento. Os sistemas de manejo do solo, foram: plantio direto (PD); preparo reduzido com uma escarificação mais uma gradagem (PRE); preparo convencional com uma lavração mais duas gradagens (PCO); preparo convencional com palha queimada (PCQ) e preparo convencional com palha retirada (PCR). Anualmente, foram aplicadas quatro fontes de nutrientes: 5 $\mathrm{t} \mathrm{ha}^{-1} \mathrm{ano}^{-1}$ de cama de aviário, base úmida (CA); $40 \mathrm{~m}^{3} \mathrm{ha}^{-}$ ${ }^{1} \mathrm{ano}^{-1}$ de dejeto líquido de suínos (DLS); $60 \mathrm{~m}^{3} \mathrm{ha}^{-1} \mathrm{ano}^{-1}$ de dejeto líquido de bovinos confinados (DLB); adubação mineral de reposição (AM) e uma testemunha, sem aplicação de nutrientes (TES). As fontes orgânicas e minerais foram aplicadas antes da última gradagem nos tratamentos com preparo do solo ou sobre a superfície do solo no PD, antes da semeadura das culturas de verão. Empregou-se, na adubação mineral, a recomendação de adubação de reposição (CFS RS/SC, 1995), aplicando-se uréia, superfosfato triplo e cloreto de potássio. As fontes orgânicas de nutrientes foram adquiridas na região e o total de $\mathrm{N}, \mathrm{P}_{2} \mathrm{O}_{5}$, e $\mathrm{K}_{2} \mathrm{O}$ aplicado nos nove anos foi, respectivamente, de $1.106,847$ e 882 $\mathrm{kg} \mathrm{ha}^{-1} \mathrm{com}$ cama de aviário; 732, 531 e $1.019 \mathrm{~kg} \mathrm{ha}^{-1} \mathrm{com}$ dejeto líquido de bovinos; $1.000,1.507$ e $526 \mathrm{~kg} \mathrm{ha}^{-1} \mathrm{com}$ dejeto líquido de suínos e 675, 450 e $690 \mathrm{~kg} \mathrm{ha}^{-1}$ com adubo mineral. Durante a condução do experimento se utilizou uma rotação de culturas com ciclos de três anos, com culturas comerciais e plantas de cobertura do solo recomendadas para a região.

No experimento foram obtidos os atributos fósforo $(\mathrm{P})$ no solo (formas lábeis), cobre $(\mathrm{Cu})$ e zinco $(\mathrm{Zn})$ extraíveis no solo, carbono orgânico total (COT), nitrogênio total (NT) e a mesofauna do solo. As determinações químicas foram realizadas em amostras coletadas ao final do nono ano de con- 
dução do experimento, nas camadas de 0-5, 5-10, 10-20 e 20$40 \mathrm{~cm}$. Os teores de Zn e Cu extraíveis e NT foram determinados segundo metodologia descrita em Tedesco et al. (1995) e o COT, conforme EMBRAPA (1997). As formas lábeis de P foram extraídas de acordo com o fracionamento proposto por Hedley et al. (1982) com modificações de Condron et al. (1985), seqüencialmente com resina trocadora de ânions (inorgânico) e $\mathrm{NaHCO}_{3}$ 0,5 mol L-1 (inorgânico e total do extrato). O P inorgânico extraído pela resina foi determinado conforme a metodologia de Murphy \& Riley (1962). Determinou-se, no extrato alcalino $\left(\mathrm{NaHCO}_{3}\right)$, o P inorgânico, pelo método de Dick \& Tabatabai (1977) e o P total por digestão com persulfato de amônio mais ácido sulfúrico em autoclave (USEPA, 1971). O P orgânico deste extrato resultou da diferença entre $\mathrm{P}$ total e $\mathrm{P}$ inorgânico extraído por bicarbonato.

As amostras de solo para estudo da mesofauna edáfica foram coletadas aproximadamente seis meses após a última aplicação dos tratamentos de manejo de solo e de fontes de nutrientes procurando-se, assim, avaliar o efeito de longo prazo dos tratamentos e não as flutuações que ocorrem logo após a sua aplicação. Duas amostras de solo foram coletadas aleatoriamente por parcela, na camada de 0-12 cm, com um trado tipo caneco com $7 \mathrm{~cm}$ de diâmetro. A avaliação da mesofauna do solo foi realizada de acordo com metodologia descrita por Quadros (2004). A contagem da fauna e a identificação a nível de grandes grupos taxonômicos, em geral a ordem, foram efetuadas manualmente após observação em microscópio estereoscópio com aumento de até 40 vezes. Aos resultados da mesofauna edáfica foi aplicado o índice de diversidade de Simpson para cada parcela, conforme a equação dada em Gliessman (2001).

O estudo do aspecto ambiental do uso das fontes de nutrientes envolveu um modelo de análise com geração de triângulos (Figura 1) e cálculo das suas áreas e dos intervalos de confiança dessas áreas. A média e o intervalo de confiança também foram determinados para os três índices usados

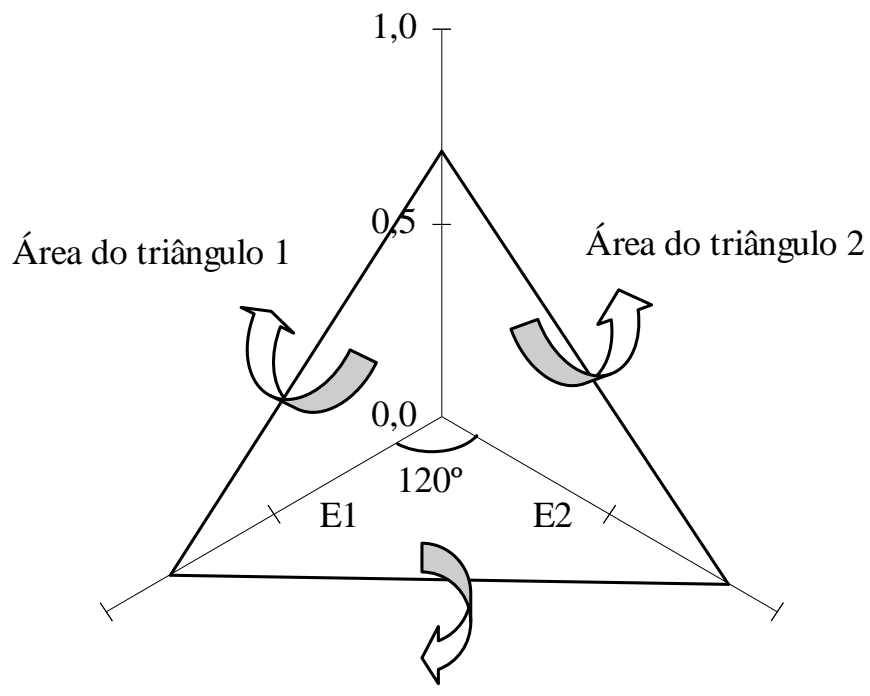

Área do triângulo 3

Figura 1. Esquema dos três triângulos internos utilizados para o cálculo da área total do triângulo determinado para cada fonte de nutrientes dentro de cada sistema de manejo do solo para a geração do triângulo, os quais se constituíram nos seus raios. Para isto, utilizaram-se atributos transformados através de relativizações, normalizações e ponderações, para que estes apresentassem valores entre zero e um. Considerou-se que os valores próximos de 1,0 refletem melhor potencial do uso das fontes (isto é, melhoria ao ambiente) e valores próximos de zero refletem um gargalo ou uma limitação no seu uso (potencialidade de dano). Os vértices dos triângulos correspondem ao valor de cada índice, plotado no raio correspondente. A área do triângulo externo correspondeu à soma das áreas dos três triângulos internos cujos lados se referem ao comprimento de dois raios adjacentes, sendo a área calculada através da fórmula $\mathrm{A}=\mathrm{E} 1 \times \mathrm{E} 2 \times($ sen $\mathrm{a} / 2)$, sendo $\mathrm{a}=120^{\circ}$ para uma figura plana de três raios (Figura 1).

No cálculo dos intervalos de confiança da área de cada triângulo e dos índices e dos atributos relativizados, utilizouse o programa@Risk 4.5. Os dados de entrada do modelo foram a média, o desvio padrão, o valor máximo e o valor mínimo de cada atributo, a partir dos quais o programa calculou 1.000 combinações dos valores dos atributos e índices, e o intervalo de confiança (limite superior e inferior) a $90 \%$ de probabilidade. As áreas ou os índices foram estatisticamente diferentes quando os intervalos de confiança, tomados dois a dois na comparação, não se sobrepuseram. $\mathrm{O}$ modelo permite todas as comparações para combinações possíveis de fontes de nutrientes e sistemas de manejo, mas são adequadas apenas as comparações entre as fontes dentro de cada sistema de manejo e entre os sistemas para uma mesma fonte.

Para avaliação do aspecto ambiental foram construídos três índices: índice de risco ambiental (IRA), composto pelas formas lábeis de $\mathrm{P}$ (orgânico + inorgânico), $\mathrm{Cu}$ e Zn extraíveis e uma avaliação da percepção de técnicos a respeito do impacto ambiental do uso de diferentes fontes de nutrientes e de sistemas de manejo do solo; índice de diversidade (ID), composto pelo índice de Simpson e, índice de carbono e nitrogênio (ICN), constituído pelos teores de COT e NT do solo.

O IRA do uso de fontes orgânicas de nutrientes em sistemas de manejo do solo foi estimado através de um índice de P (IPo), um índice de metal (IM) e o índice de percepção dos técnicos (IPT). Para determinação do IPo se utilizaram formas lábeis de $\mathrm{P}$, atributo este que foi associado ao risco de eutrofização das águas pela possibilidade de transferência do sistema solo para água, através da erosão. O índice de metal (IM) foi calculado utilizando-se os teores de $\mathrm{Cu}$ mais $\mathrm{Zn}$ disponíveis, que dizem respeito ao risco de elevação do teor de metais pesados no solo e sua inserção na cadeia alimentar, a partir da absorção pelas plantas. O IPT, por sua vez, considerou a percepção de vários profissionais que exercem suas atividades na área de agronomia, a respeito de questões ambientais do uso de fontes orgânicas de nutrientes e de sistemas de manejo de solo, que se associou ao risco de problemas ambientais diversos pelo uso das fontes orgânicas de nutrientes e dos sistemas de manejo de solo.

Para a relativização do P total lábil e cálculo do IPo, considerou-se não apenas a sua concentração total no solo mas também a sua distribuição na camada de $0-40 \mathrm{~cm}$. Na distri- 
buição do P levou-se em conta que o risco de contaminação ambiental é tanto maior quanto maior for teor na superfície (acúmulo superficial) ou em profundidade (lixiviação) e que sua distribuição no perfil deveria ser uniforme. Assim, foram calculados os desvios do $\mathrm{P}$ total em cada camada (DP) em relação ao valor médio do $P$ nas quatro camadas, através da equação:

$$
\mathrm{DP}=\sum_{i=1}^{4}\left[(\mathrm{Pti}-\bar{x} \mathrm{Pt})^{2} / \overline{\mathrm{x}} \mathrm{Pt}\right]
$$

donde: DP é o desvio do fósforo total (Pt); Pti é o teor de Pt na camada i; $\bar{x}$ Pt é a média ponderada dos teores de Pt das quatro camadas e $i$ é a camada amostrada.

Os valores de DP foram relativizados pelo valor mínimo encontrado entre todas as parcelas, através da equação:

$$
\mathrm{DP}_{\mathrm{r}}=\log \left(\mathrm{DP}_{\min }+10\right) / \log \left(\mathrm{DP}_{\text {parc }}+10\right)
$$

donde: DPr é o DP relativizado da parcela; DP min o menor desvio encontrado e DP parc é o desvio da parcela.

Com relação à concentração de Pt no solo, relativizaramse as médias de Pt na camada de $0-40 \mathrm{~cm}$ pelo valor mínimo de Pt encontrado nas parcelas $(\mathrm{Ptr}=\mathrm{Ptmin} / \mathrm{Pt}$ parcela), ou seja, quanto menor o valor de Pt menor também o risco e maior o valor que irá compor o IPo. O IPo foi composto pela média da DPr e do Ptr.

Para a relativização do $\mathrm{Zn}$ e do $\mathrm{Cu}$ e cálculo do IM, procedeu-se da mesma maneira como para o Pt, levando-se em conta a concentração e a distribuição desses na camada de $0-40 \mathrm{~cm}$, dando origem ao índice de zinco (IZn) e índice de cobre (ICu). O índice de metais (IM), por sua vez, correspondeu à média aritmética do $\mathrm{IZn}$ e do $\mathrm{ICu}$.

Para a avaliação do impacto ambiental do uso de fontes de nutrientes e sistemas de manejo do solo através da percepção e experiência de técnicos que atuam na área, dois questionários foram elaborados: um para detectar a interpretação sobre o impacto ambiental do uso de fontes de nutrientes e o outro sobre o impacto ambiental dos sistemas de manejo de solo, os quais foram respondidos por 35 técnicos.

Em relação às fontes de nutrientes, foram consultados: a) quanto a problemas ocasionados pelo uso das fontes de nutrientes; b) quanto ao gasto de energia fóssil até a produção das fontes e c) quanto a outras externalidades. Em adendo a essas perguntas, outras duas foram adicionadas com o objetivo de se avaliar a testemunha (sem adição de fontes de nutrientes, porém cultivado), relacionando-as ao risco de degradação das propriedades químicas, físicas e biológicas e quanto ao risco de comprometimento da qualidade da água no meio rural e urbano. Relativo ao impacto ambiental dos sistemas de manejo de solo, foram consultados: a) quanto ao risco de erosão do solo; b) em relação ao risco de escoamento superficial; c) no que diz respeito ao consumo de combustível fóssil; d) quanto ao risco de degradação da qualidade do solo; e) quanto ao uso de agroquímicos e f) relativo às externalidades do uso desses manejos. Calculou-se, para cada fonte, a média da pontuação obtida nas cinco respostas de todos os participantes. O IPT se constituiu da combinação dos resultados de cada fonte de nutrientes e testemunha com os diferentes sistemas de manejo do solo. O resultado de cada fonte foi somado ao resultado de cada sistema de manejo do solo e dividido por dois, resultando em 25 índices. Consideraram-se no programa @RISK 4.5 apenas os valores médios desses índices.

O IRA correspondeu à média ponderada dos atributos individuais, atribuindo-se um peso de $60 \%$ para IPo, 20\% para o IM e 20\% para IPT. Esses pesos foram considerados tendo em vista que o potencial de contaminação ambiental pelo $P$ é grande quando em teores elevados no solo. Para os metais pesados, especialmente $\mathrm{Zn}$ e $\mathrm{Cu}$, não se tem bem claro quais são as suas consequiências no ambiente nem quais são os níveis críticos considerados poluidores ao ambiente (solo, planta etc.), razão pela qual se lhe conferiu um peso de $20 \%$. Ao IPT se atribuiu também o peso de $20 \%$, por se tratar de uma avaliação subjetiva.

A normalização do índice de diversidade (ID) foi baseada em Gliessman (2001), que considerou que ecossistemas naturais relativamente diversificados apresentam índices de Simpson iguais ou maiores do que cinco. Considerou-se, então, que os índices de Simpson acima de 5,0 têm peso de 1,0 , o menor índice tem peso de 0,7 e os intermediários estimados a partir de uma regressão segmentada com patamar, em que $\hat{y}=0,75 x+0,624$ para IS $\leq 5$ e $\hat{y}=1$ para, IS $>5$.

Os dados de COT e NT do solo foram relativizados (COTr e NTr, respectivamente) tomando-se como referência os teores máximos de carbono e de nitrogênio encontrados nas parcelas, na camada de $0-20 \mathrm{~cm}$. Considerou-se índice carbono-nitrogênio (ICN) a média das duas relativizações em cada tratamento.

\section{RESULTADOS E DISCUSSÃO}

Na Figura 2 se apresentam, a título de exemplo, triângulos construídos com os três índices cujas áreas se referem ao aspecto ambiental do uso das respectivas fontes de nutrientes, em dois sistemas de manejo contrastantes.

Observa-se que houve tendência de diferenciação visual entre as fontes de nutrientes quanto ao aspecto ambiental, nos sistemas PD e PCR; entretanto, para todas as fontes e para os dois sistemas de manejo do solo, o IRA foi o índice que se manteve mais afastado em relação ao ponto máximo $(1,0)$, indicando um desempenho ambiental pior deste índice em relação aos demais. No PCR, apesar de ter havido menor variabilidade entre os índices, os triângulos são menores, indicando um desempenho pior das fontes no aspecto ambiental em relação ao PD, pois os três índices estão comprometidos. Entre os três índices que compõem o aspecto ambiental do uso das fontes nos sistemas PD e PCR, o IRA indicou os menores valores, sugerindo que todas as fontes mostram um potencial de risco de dano ao ambiente considerando-se os parâmetros e pesos utilizados, ou seja, limitação de uso. Por outro lado, todas as fontes de nutrientes e a testemunha (sem aplicação de nutrientes), mostraram IRA mais baixos e semelhantes. Os baixos valores do IRA e a não 

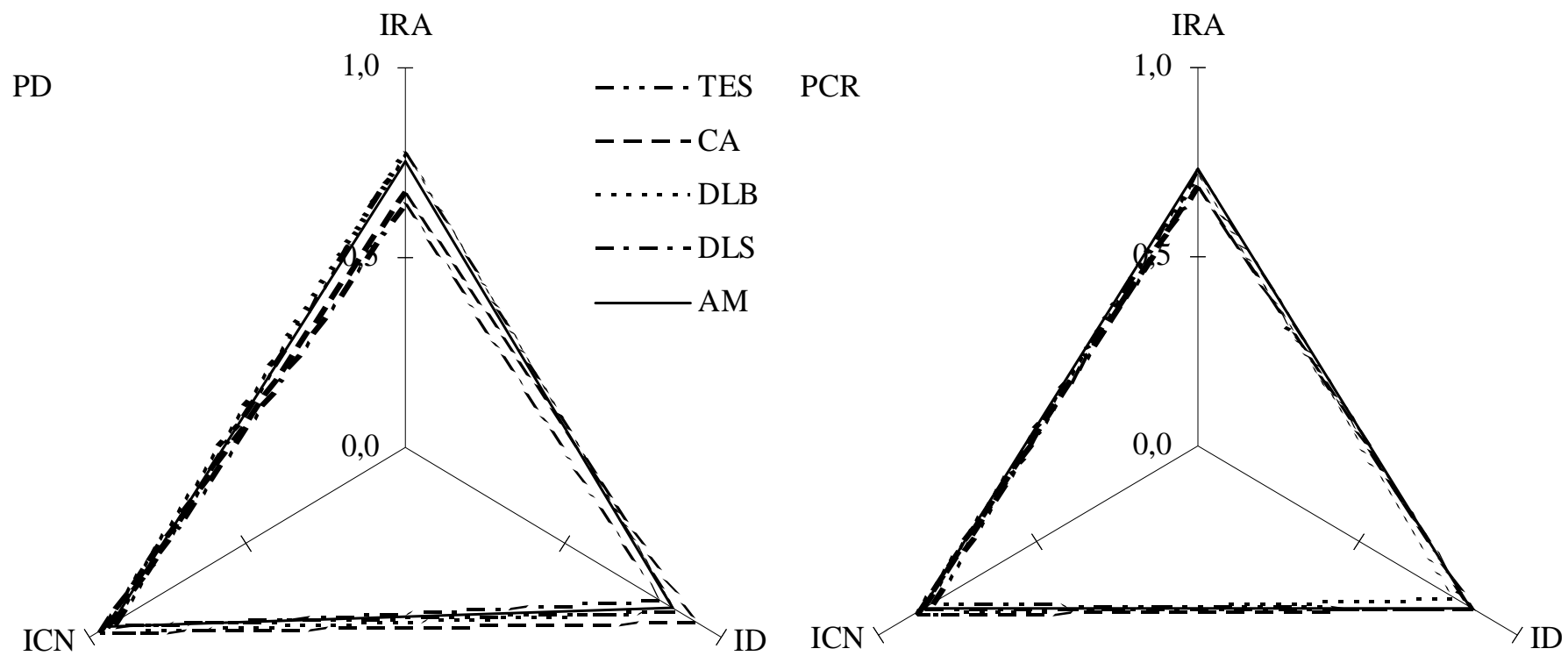

Figura 2. Aspecto ambiental do uso de fontes de nutrientes para os sistemas de manejo do solo PD e PRE, compostos pelo índice de risco ambiental (IRA), índice de diversidade (ID) e índice de carbono e nitrogênio (ICN)

diferenciação em magnitude dos mesmos podem ser explicados pela falta de padrões de referência dos atributos quanto aos limites de dano e aos pesos atribuídos empiricamente.

As maiores áreas médias do aspecto ambiental, excluindo-se a testemunha, foram apresentadas, de maneira geral, pelas fontes DLB, AM e CA, variando com o sistema de manejo do solo (Tabela 1), ao passo que a menor área foi apresentada pelo DLS (exceto no PCR), constituindo-se na fonte que diferiu significativamente mais vezes nas comparações possíveis entre estas.

Verificaram-se diferenças no aspecto ambiental entre as fontes. Em 50\% das comparações entre o DLS e as outras fontes, este apresentou desempenho significativamente menor quanto ao aspecto ambiental. As fontes CA, DLB, AM e TES não diferiram entre si, exceto em três comparações entre 30 possíveis. O DLS mostrou, então, maior potencial de dano ao ambiente, mas Seganfredo et al. (2003), analisando a presença de coliformes fecais em rios de regiões suínicolas no município de Jaborá, SC, verificaram que os dejetos suínos não foram as únicas fontes poluidoras dos rios no meio rural, embora os autores alertem para o fato de que o uso do DLS como fertilizante representa risco de poluição microbiana das águas. Não só o dejeto de suínos é considerado impactante ao ambiente mas, também, a atividade suinícola em si, como demonstrou Spies (2003) em seu estudo realizado em Santa Catarina, ao concluir que os sistemas de produção de suínos no Estado causam impacto ambiental $68 \%$ maior que o sistema de produção de aves, quando comparado a uma unidade funcional de suínos com uma de aves. No caso da CA, Moore Jr. et al. (1995) consideraram que, apesar de se tratar de um dos melhores fertilizantes orgânicos, a aplicação de doses altas pode levar à lixiviação de nitrato para o lençol freático, escoamento superficial de $\mathrm{P}$ para corpos de água adjacentes e, possivelmente, elevar os níveis de patógenos (bactérias e vírus) nos lagos e rios.
Com relação ao ICN, as fontes de nutrientes não diferenciaram entre si, exceto a testemunha que se diferenciou das demais fontes no PCO apresentando, em geral, valores mais baixos (Tabela 1). A não diferenciação pode estar associada às quantidades de dejetos aplicadas e à profundidade do solo considerada $(0-20 \mathrm{~cm})$, pois maiores acúmulos de MO ocorrem nas camadas superficiais do solo. Por outro lado, Houtin et al. (1997) demonstraram que o conteúdo de $\mathrm{C}$ e $\mathrm{N}$ no solo aumentou com o crescimento das taxas de DLS aplicadas (aplicações de 0 a $120 \mathrm{~m}^{3} \mathrm{ha}^{-1}$ ) por 14 anos, em solo com $22 \%$ de argila. Segundo esses autores, os dados sugeriram que a aplicação de doses altas de DLS durante longo período resulta em uma concentração total maior de $\mathrm{C}, \mathrm{N}$ e $\mathrm{P}$ no perfil. De forma geral, as fontes orgânicas de nutrientes mostraram ICN mais altos que a testemunha e o AM, sugerindo que a adição dos dejetos tendeu a aumentar o ICN no solo. Entretanto, quando em áreas sob pastagem natural e com a retirada da matéria seca pelos animais, mesmo após 28 aplicações de DLS em um período de quatro anos, com doses de até $40 \mathrm{~m}^{3} \mathrm{ha}^{-1}$ por aplicação, não se observou alteração nos teores de C e N no solo (Ceretta et al., 2003).

Quanto ao ID, 14 das 50 comparações possíveis foram diferentes estatisticamente e a CA esteve presente em sete delas. A cama de aviário, que apresentou os maiores valores entre as fontes orgânicas, e o DLS, que na maioria das vezes mostrou os menores valores, foram diferentes entre si nos sistemas de manejo PD, PCO e PCQ. Esta pequena diferenciação pode ser devida à época de avaliação da mesofauna, que foi realizada em uma única vez, aproximadamente seis meses após a aplicação dos tratamentos de fontes e de sistemas de manejo. Neste sentido, Petersen (2002) verificou alta redução no número de colêmbolos uma semana após a aplicação de tratamentos de preparo do solo mas Bandyopadhyaya et al. (2002), estudando o efeito de alguns fatores físicos e práticas agrícolas em colêmbolos, constataram que a aplicação de dejetos induziu a um aumento na sua popula- 
Tabela 1. Média, limite superior e inferior da área da figura do aspecto ambiental, do índice de carbono e nitrogênio (ICN), do risco ambiental (IRA) e de diversidade (ID), para as fontes de nutrientes associadas a sistemas de manejo do solo

\begin{tabular}{|c|c|c|c|c|c|c|c|c|c|c|c|c|c|}
\hline \multirow{2}{*}{ Manejo $^{1}$} & \multirow{2}{*}{ Fonte $^{2}$} & \multicolumn{3}{|c|}{ Área da figura } & \multicolumn{3}{|c|}{ ICN } & \multicolumn{3}{|c|}{ IRA } & \multicolumn{3}{|c|}{ ID } \\
\hline & & Média & Inf. & Sup. & Média & Inf. & Sup. & Média & Inf. & Sup. & Média & Inf. & Sup. \\
\hline \multirow{5}{*}{ PD } & TES & 0,925 & 0,854 & 0,990 & 0,911 & 0,870 & 0,952 & 0,768 & 0,717 & 0,822 & 0,855 & 0,790 & 0,913 \\
\hline & $C A$ & 0,909 & 0,877 & 0,940 & 0,951 & 0,919 & 0,981 & 0,660 & 0,638 & 0,679 & 0,915 & 0,893 & 0,935 \\
\hline & DLB & 0,952 & 0,905 & 1,001 & 0,954 & 0,920 & 0,985 & 0,770 & 0,723 & 0,812 & 0,849 & 0,822 & 0,877 \\
\hline & DLS & 0,807 & 0,760 & 0,850 & 0,936 & 0,907 & 0,964 & 0,637 & 0,628 & 0,647 & 0,806 & 0,744 & 0,862 \\
\hline & $A M$ & 0,914 & 0,838 & 0,987 & 0,929 & 0,901 & 0,957 & 0,750 & 0,719 & 0,781 & 0,842 & 0,747 & 0,927 \\
\hline \multirow{5}{*}{ PRE } & TES & 0,995 & 0,948 & 1,042 & 0,916 & 0,898 & 0,936 & 0,761 & 0,730 & 0,793 & 0,955 & 0,902 & 1,000 \\
\hline & $\mathrm{CA}$ & 0,866 & 0,821 & 0,913 & 0,943 & 0,927 & 0,961 & 0,676 & 0,644 & 0,706 & 0,842 & 0,788 & 0,893 \\
\hline & DLB & 0,900 & 0,845 & 0,954 & 0,934 & 0,909 & 0,961 & 0,743 & 0,691 & 0,792 & 0,825 & 0,785 & 0,869 \\
\hline & DLS & 0,826 & 0,762 & 0,887 & 0,941 & 0,894 & 0,987 & 0,634 & 0,620 & 0,650 & 0,832 & 0,750 & 0,905 \\
\hline & AM & 0,899 & 0,870 & 0,927 & 0,953 & 0,924 & 0,979 & 0,723 & 0,699 & 0,747 & 0,828 & 0,813 & 0,843 \\
\hline \multirow{5}{*}{ PCO } & TES & 0,847 & 0,786 & 0,907 & 0,893 & 0,858 & 0,928 & 0,721 & 0,693 & 0,748 & 0,813 & 0,739 & 0,885 \\
\hline & CA & 0,832 & 0,804 & 0,861 & 0,989 & 0,971 & 1,000 & 0,623 & 0,593 & 0,657 & 0,810 & 0,799 & 0,819 \\
\hline & DLB & 0,879 & 0,828 & 0,925 & 0,958 & 0,941 & 0,976 & 0,712 & 0,695 & 0,729 & 0,807 & 0,740 & 0,867 \\
\hline & DLS & 0,755 & 0,724 & 0,786 & 0,967 & 0,935 & 0,995 & 0,585 & 0,556 & 0,614 & 0,759 & 0,742 & 0,775 \\
\hline & $A M$ & 0,918 & 0,883 & 0,955 & 0,957 & 0,935 & 0,979 & 0,677 & 0,653 & 0,704 & 0,901 & 0,868 & 0,938 \\
\hline \multirow{5}{*}{ PCQ } & TES & 0,867 & 0,796 & 0,935 & 0,889 & 0,842 & 0,938 & 0,757 & 0,722 & 0,796 & 0,806 & 0,733 & 0,877 \\
\hline & $C A$ & 0,920 & 0,854 & 0,959 & 0,917 & 0,889 & 0,947 & 0,654 & 0,646 & 0,661 & 0,971 & 0,875 & 1,000 \\
\hline & DLB & 0,892 & 0,805 & 0,982 & 0,901 & 0,850 & 0,951 & 0,703 & 0,673 & 0,732 & 0,888 & 0,777 & 1,000 \\
\hline & DLS & 0,793 & 0,757 & 0,830 & 0,902 & 0,858 & 0,944 & 0,650 & 0,618 & 0,682 & 0,802 & 0,788 & 0,816 \\
\hline & $A M$ & 0,890 & 0,841 & 0,940 & 0,872 & 0,817 & 0,927 & 0,717 & 0,678 & 0,757 & 0,900 & 0,887 & 0,913 \\
\hline \multirow{5}{*}{ PCR } & TES & 0,824 & 0,757 & 0,902 & 0,819 & 0,761 & 0,876 & 0,721 & 0,661 & 0,782 & 0,852 & 0,792 & 0,918 \\
\hline & CA & 0,833 & 0,811 & 0,856 & 0,869 & 0,845 & 0,892 & 0,679 & 0,664 & 0,694 & 0,861 & 0,845 & 0,878 \\
\hline & DLB & 0,809 & 0,766 & 0,853 & 0,874 & 0,830 & 0,918 & 0,703 & 0,684 & 0,723 & 0,795 & 0,753 & 0,836 \\
\hline & DLS & 0,814 & 0,782 & 0,846 & 0,853 & 0,817 & 0,888 & 0,673 & 0,649 & 0,698 & 0,856 & 0,839 & 0,873 \\
\hline & AM & 0,854 & 0,807 & 0,902 & 0,848 & 0,795 & 0,899 & 0,734 & 0,696 & 0,773 & 0,852 & 0,835 & 0,869 \\
\hline
\end{tabular}

${ }^{1} \mathrm{PD}=$ Plantio direto PRE = Preparo reduzido PCO = Preparo convencional $\mathrm{PCQ}=$ Preparo convencional com palha queimada; $\mathrm{PCR}=\mathrm{Preparo}$ convencional com palha retirada

${ }^{2} \mathrm{TES}=$ Testemunha (sem aplicação de nutrientes); CA = Cama de aviário; DLB = Dejeto líquido de bovinos; DLS = Dejeto líquido de suínos; AM = Adubo mineral

ção, porém a sazonalidade climática e o tipo de cultura exerceram maior efeito na população.

As fontes de nutrientes se diferenciaram entre si quanto ao IRA (Tabela 1), com 20 comparações das 50 possíveis diferindo significativamente. Em geral, a testemunha apresentou os maiores valores de IRA (menor risco ambiental), quando comparadas com as demais fontes. Embora ambientalmente isto seja interessante, tecnicamente não o é porque os cultivos contínuos comprometerão cada vez mais a produtividade das culturas, pela extração e diminuição na disponibilidade de nutrientes às plantas. Além da TES, as fontes que aportaram ao solo menores quantidades de nutrientes, especialmente $\mathrm{P}, \mathrm{Cu}$ e $\mathrm{Zn}$ e, conseqüentemente, favoreceram menor acúmulo dos mesmos no solo, foram o DLB e a AM, apresentando um risco ambiental menor (maior IRA). Com relação às fontes orgânicas de nutrientes, a CA e o DLS não se diferenciaram em nenhum dos sistemas de manejo do solo, sendo que ambas apresentaram o maior risco ambiental (menor IRA), demonstrando que, mesmo nas doses utilizadas, que foram baseadas em estudos realizados com solos e culturas semelhantes aos utilizados neste experimento, houve risco ambiental com as doses aplicadas, sugerindo que o risco ambiental pode crescer com o aumento das doses de dejetos aplicadas, principalmente daqueles dejetos que apresentarem maiores concentrações de nutrientes. Neste sentido, Chang et al. (1991) ve- rificaram que o acúmulo de $\mathrm{Zn}$, Mo, $\mathrm{P}$ total e disponível no solo aumentou com o aumento das taxas de dejeto bovino aplicado durante 11 anos. Adicionalmente, Ceretta et al. (2005), em um trabalho com aplicação de doses de DLS em Argissolo Vermelho Distrófico arênico, verificaram que a recuperação de N, P e K pelas plantas atingiu o máximo até doses intermediárias, como $40 \mathrm{~m}^{3} \mathrm{ha}^{-1}$, evidenciando que doses mais altas são menos eficientes à nutrição das plantas e potencializam os riscos de contaminação do solo e da água. Isso ficou igualmente evidenciado quando Durigon et al. (2002) utilizaram doses de DLS em pastagem natural no Rio Grande do Sul.

Ao se comparar a mesma fonte entre os sistemas de manejo do solo verificou-se que, de modo geral, o melhor desempenho quanto ao aspecto ambiental (maior área da figura) decresceu na ordem PD > PRE > PCQ > PCO > PCR (Tabela 1). O pior desempenho ambiental do PCR em relação ao PD se deveu, provavelmente, ao ICN e ao ID (Figura 2).

\section{CONCLUSÕES}

1. As fontes de nutrientes exerceram efeitos diferenciados quanto ao aspecto ambiental. 
2. O dejeto líquido de suínos foi a fonte que apresentou maior impacto negativo ao ambiente, enquanto o dejeto líquido bovino e a adubação mineral indicaram menor impacto.

3. Dentre os três índices avaliados, o índice de risco ambiental foi o que apresentou menores valores, demonstrando ser o mais crítico ao ambiente considerando-se os parâmetros e pesos utilizados.

\section{LITERATURA CITADA}

Angle, J. S.; Gross, C. M.; Hill, R.L.; McIntosh, M. S. Soil nitrate concentrations under corn as affected by tillage, manure, and fertilizer applications. Journal Environmental Quality, v.22, n.1, p.141-147, 1993.

Bandyopadhyaya, I.; Choudhuri, D. K.; Ponge, J. F. Effects of some physical factors and agricultural practices on Collembolla in a multiple cropping programme in west Bengal (India). European Journal Soil Biology, v.38, n.1, p.111-117, 2002.

Bouchard, D. C.; Williams, M. K.; Surampalli, R. Y. Nitrate contamination of groundwater: Sources and potential health effects. Journal of the American Water Works Association, v.84, n.9, p.85-90, 1992.

Ceretta, C. A.; Basso, C. J.; Pavinato, P. S.; Trentin, E. E.; Girotto, E. Produtividade de grãos de milho, produção de matéria seca e acúmulo de nitrogênio, fósforo e potássio na rotação aveia preta/milho/nabo forrageiro com aplicação de dejeto líquido de suínos. Ciência Rural, v.35, n.6, p.1287-1295, 2005.

Ceretta, C. A.; Durigon, R.; Basso, C. J.; Barcellos, L. A. R.; Vieira, F.C.B. Características químicas de solo sob aplicação de dejeto líquido de suínos em pastagem natural. Pesquisa Agropecuária Brasileira, v.38, n.6, p.729-735, 2003.

CFS RS/SC - Comissão de Fertilidade do Solo. Recomendações de adubação e de calagem para os estados do Rio Grande do Sul e de Santa Catarina. 3.ed. Passo Fundo: EMBRAPACNPT/SBCS - Núcleo Regional Sul, 1995. 224p.

Chang, C.; Sommerfeldt, T. G.; Entz, T. Soil chemistry after eleven annual applications of cattle feedlot manure. Journal Environmental Quality, v.20, n.2, p.475-480, 1991.

Condron, L. M.; Goh, K. M.; Newman, R. H. Nature and distribution of soil phosphorus as revealed by a sequential extraction method followed by 31P nuclear magnetic resonance analysis. Journal of Soil Science, v.36, n.1, p.199-207, 1985.

Dick, W. A.; Tabatabai, M. A. Determination of orthophosphate in aqueous solutions containing labile organic and inorganic phosphorus compounds. Journal of Environmental Quality, v.6, n.1, p.82-85, 1977.

Durigon, R.; Ceretta, C. A.; Basso, P. C. J.; Barcellos, L. A. R.; Pavinatto, P. S. Produção de forragem em pastagem natural com o uso de dejeto líquido de suínos. Revista Brasileira de Ciência do Solo, v.26, n.4, p.983-992, 2002.

EMBRAPA - Empresa Brasileira de Pesquisa Agropecuária. Centro Nacional de Pesquisa de Solos. Manual de métodos de Análise de solo. 2.ed. Rio de Janeiro: Embrapa Solos, 1997. 212p.

EMBRAPA - Empresa Brasileira de Pesquisa Agropecuária. Centro Nacional de Pesquisa de Solos. Sistema brasileiro de classificação de solos. 2.ed. Rio de Janeiro: Embrapa Solos , 2006. 306p.
Etana, A.; Hakansson, I.; Zagal, E.; Bucas, S. Effects of tillage depth on organic carbon content and physical properties in five Swedish soils. Soil \& Tillage Research, v.52, n.3-4, p.129-139, 1999.

Gliessman, S. R. Agroecologia: Processos ecológicos em agricultura sustentável. 2.ed. Porto Alegre: UFRGS, 2001. 653p.

Hedley, M. J.; Stewart, J. W. B.; Chauhan, B. S. Changes in inorganic and organic soil phosphorus fractions induced by cultivation practices and by laboratory incubations. Soil Science Society of American Journal, v.46, n.4, p.970-976, 1982.

Houtin, J. A.; Coillard, D.; Karam, A. Soil carbon, nitrogen and phosphorus contents in maize plots after 14 years of pig slurry applications. Journal of Agricultural Science, v.129, n.2, p.187-191, 1997.

Hunter, C. H.; Perkins, J. T.; Hardwick, P. Fecal bacteria in the waters of an upland area in Derbshire, England: The influence of agricultural land use. Journal of Environmental Quality, v.29, n. 4, p.1253-1261, 2000.

ICEPA/SC - Instituto de Planejamento e Economia Agrícola de Santa Catarina. Secretaria do Estado da Agricultura e Desenvolvimento Rural. Levantamento agropecuário de Santa Catarina 2002-2003. 2005. 255p. Dados Preliminares

McMurry, S. W.; Coyne, M. S.; Perfect, E. Fecal coliform transport through intact soil blocks amended with poultry manure. Journal Environmental Quality, v.27, n.1, p.86-92, 1998.

Moore Jr., P. A.; Daniel, T. C.; Sharpley, A. N.; Wood, C. W. Poultry manure management: Environmentally sound options. Journal of Soil and Water Conservation, v.50, n.3, p.321-327, 1995.

Muchovej, R. M. C.; Obreza, T. A. Application of organic wastes in agriculture. In: Alvarez, V. H; Fontes, L. E. F.; Fontes, M. P. F. (eds.). O solo nos grandes domínios morfoclimáticos do Brasil e o desenvolvimento sustentado. Viçosa: SBCS/UFV/DPS, 1996. p.901-914.

Murphy, J.; Riley, J. P. A modified single solution method for the determination of phosphate in natural waters. Analytica Chimica Acta, v.27, n.1, p.31-36, 1962.

Petersen, H. Effects of non-inverting deep tillage vs. conventional ploughing on collembolan populations in an organic wheat field. European Journal of Soil Biology, v.38, n.2, p.177-180, 2002.

Quadros, V. J. D. Fauna edáfica, associações biológica e atributos econômicos em sistemas de cultivo orgânico de batata, soja, feijão e milho. Santa Maria: UFSM, 2004. 107p. Dissertação Mestrado

Scherer, E. E.; Castilhos, E. G. D.; Jucksch, I.; Nadal, R. D. Efeito da adubação com dejeto de suínos, nitrogênio e fósforo em milho. Florianópolis: EMPASC, 1984. 26p. Boletim Técnico, 24

Scherer, E. E.; D’Agostini, V. J.; Wildner, L. D. P.; Nadal, R. D.; Silvestro, M. L.; Sorrenson, W. J. Dejeto de aves e nitrogênio em milho nas pequenas propriedades. Agropecuária Catarinense, v.4, n.2, p.8-11, 1991.

Seganfredo, M. A.; Soares, I. J.; Klein, C. S. Qualidade da água de rios em regiões suinícolas do município de Jaborá SC. In: Congresso Brasileiro de Veterinários Especialistas em Suínos, 11, 2003, Goiânia. Anais... Concórdia: Embrapa Suínos e Aves, 2003, CD Rom

Sharpley, A. N.; Hedley, M. J.; Sibbesen, E.; Hillbricht-Ilkowska, A.; House, W. A.; Ryszkowski, L. Phosphorus tranfers from terrestrial to aquatic ecosystems, In: Tiessen, H. (ed). Phosphorus in the global environment (tranfers, cycles and management). London: John Wiley \& Sons Ltd., 1995. p.171-199. 
Spies, A. The sustainability of the pig and poultry industries in Santa Catarina, Brazil: a framework of change. Brisbane: University of Queensland, School of Natural and Rural Systems Management, 2003. 379p. Tese Doutorado

Stoddard, C. S.; Coyne, M. S.; Grove, J. H. Fecal bacteria survival and infiltration through a shallow agricultural soil: Timing and tillage effects. Journal Environmental Quality, v.27, n.6, p.1516-1523, 1998.
Tedesco, M. J.; Gianello, C.; Bissani, C. A.; Bohnen, H.; Volkweiss, S. J. Análises de solo, plantas e outros materiais. 2.ed. Porto Alegre: UFRGS/Departamento de Solos, 1995. 174p. Boletim Técnico, 5

USEPA - United States Environmental Protection Agency. Methods of chemical analysis for water and wastes. Cincinnati: USEPA, 1971. 312p. 